\title{
LICENCIATURA EM EDUCAÇÃO DO CAMPO: DAS SEMENTES AOS RAMOS DE SOL DESTA LUTA - TURMA OSEAS CARVALHO: PRESENTE, PRESENTE, PRESENTE!
}

Undergraduate degree in rural education: From seeds to branches of sun of this fight Oseas Carvalho class: Present, present, present!

\author{
Larissa Silva Douetts \\ Graduada em Geografia pela Faculdade de Formação de Professores. Militante do Movimento \\ dos Trabalhadores Rurais Sem Terra \\ Laradouetts@gmail.com
}

Artigo recebido em 06/09/2013 e aceito para publicação em 10/11/2013

DOI: 10.12957/tamoios.2013.7358

RESUMO Este texto pretende abordar a construção cotidiana da primeira turma de Licenciatura em Educação do Campo (LEC) no Estado do Rio de Janeiro, que está sendo implementada desde 2010 na Universidade Federal Rural do Rio de Janeiro (UFRRJ), enfocando a centralidade dos movimentos sociais e dos sujeitos que a compõem. Partindo do histórico da construção da educação do campo, podemos enfim compreender o processo que se construiu e que foi construído a partir das lutas e enfim, chegando ao Rio de Janeiro, através do Edital PRONERA/2009 que implementou a turma Oseas Carvalho.

Palavras-chave: Educação do Campo; Licenciatura em Educação do Campo; Turma Oseas Carvalho; PRONERA 2009.

ABSTRACT This text addresses the daily construction of the first class of Bachelor in Rural Education (CLE) in the State of Rio de Janeiro, which is being implemented since 2010 in the Federal Rural University of Rio de Janeiro (UFRRJ), focusing on the centrality of social movements and individuals who compose it. Based on the historical construction of the field of education, we can finally understand the process that is built and it was built from the struggles and finally coming to Rio de Janeiro, through Proclamation PRONERA/2009 that implemented the class Oseas Carvalho.

Keywords: Rural Education; Degree in Rural Education; Oseas Carvalho Class; PRONERA 2009. 
Escrevo esta canção porque é preciso.

Se não a escrevo, falho com o pacto

Que tenho abertamente com a vida.

(...)

E nos dois lados deste muro

Que atravessa a esperança da cidade

Onde encontrei o amor

- o homem está

Ficando seco como um sapo seco

E a sua casa já se transformou

Em apenas local de seu refúgio.

(...)

Lá na terra marcada como um boi

Pela brasa do latifúndio.

É preciso ajudar.

Porém primeiro, para poder fazer o necessário,

É preciso ajudar-me, agora mesmo,

A ser capaz de amor.(...)

(Thiago de Mello - É preciso fazer alguma coisa)

\section{EDUCAÇÃO DO CAMPO - AS SEMENTES, OS FRUTOS E A RAIZ}

Para iniciarmos uma conversa sobre educação do campo, uma das primeiras coisas que precisamos compreender é quem são os sujeitos dessa luta: os trabalhadores e trabalhadoras do campo em sua dinâmica histórica.

A Educação do Campo nomeia um fenômeno da realidade brasileira atual, protagonizado pelos trabalhadores do campo e suas organizações, que visa incidir sobre a política de educação desde os interesses sociais das comunidades camponesas (CALDART, 2012. p 257)

A discussão sobre Educação do Campo surge através do protagonismo dos movimentos sociais do campo em estado de luta - principalmente o Movimento dos Trabalhadores Rurais Sem Terra (MST). O surgimento desta expressão - Educação do Campo - data da I Conferência Nacional por uma Educação do Campo, realizada em julho de 1998, momento em que deixou de ser chamada de Educação Básica do Campo e passou a ser conhecida como Educação do Campo de fato.

O debate acerca da Educação do Campo só ganha sentido no campo conceitual quando nos auxilia a perceber as lutas que nos desafiam no presente e no futuro, porém sem nunca esquecer as lutas dos que vieram antes de nós. Aí reside a importância da militância e do entendimento de que a Educação do Campo trata dos sujeitos do campo e dos processos de formação social nos quais estes se encontram. 
A Educação do Campo surgiu da luta contra a lógica que pensa o campo apenas a partir dos interesses do grande capital, que oprime e expulsa famílias porque delas já não precisa, é a resistência contra a cultura imposta do agronegócio que só precisa de trabalhadores treinados em sua lógica mecanicista. Ela luta para que a educação se aproxime de suas demandas e de sua realidade específica - mas que nem por isso representa a realidade de uma minoria - por estar ligada aos interesses da agricultura familiar a Educação do Campo trabalha com um segmento social que produz diretamente a sustentação da vida no Brasil e em qualquer lugar do mundo. $\mathrm{E}$ quando falamos da Educação do Campo, falamos desse campo da resistência e da vida:

(...)quando se trata o agro como mero negócio (agronegócio) a terra é de fato mera mercadoria que pode ser transacionada sem maiores preocupações, diferentemente de quando o agro é lugar de vida (agricultura) e a terra, portanto, não é uma mera mercadoria(ALENTEJANO, 2011. P 6)

Desta forma, quando tratamos da produção de alimentos, podemos perceber:

Se compararmos o crescimento da população brasileira com o crescimento da produção agrícola, verificaremos que o quadro de insegurança alimentar se evidencia. Entre 1991 e 2012, a população brasileira passou de 146.917.459 habitantes para 190.715.799 habitantes, um crescimento de $29,8 \%$. No mesmo período, a produção de arroz aumentou $33 \%$ e a de feijão $27 \%$, ou seja, a de arroz superou levemente o crescimento populacional e a de feijão ficou abaixo deste, o que significa dizer que caiu a disponibilidade de feijão por habitante, o que explica que este produto seja importado hoje até da China. Por outro lado, a produção de milho cresceu $237 \%$, a de cana-de-açúcar $255 \%$ e a de soja $288 \%$, o que confirma a prioridade da agricultura brasileira atual pelos produtos voltados para a exportação ou a produção de matérias primas para a indústria em detrimento da produção de alimentos para a população (ALENTEJANO, 2011. PÁGINAS 16 E 17)

Esta luta pela Educação do Campo parte da resistência como forma de se rebelar e questionar a forma de tratamento dada ao trabalhador e à trabalhadora do campo e da cidade, desde a relação com a produção de alimentos bem como o próprio lugar social em que esses sujeitos encontram-se localizados, buscando alternativas ao que até agora tem sido feito. É uma luta para acabar com a invisibilidade histórica dos sujeitos da agricultura familiar no Brasil.

E para além de toda a luta, permanece o sonho.

Sonhar não faz parte dos trinta direitos humanos que as Nações Unidas proclamaram no final de 1948. Mas, se não fosse por causa do direito de sonhar e pela água que dele jorra, a maior parte dos direitos morreria de sede. Deliremos, pois, por um instante. O mundo, que hoje está de pernas para o ar, vai ter de novo os pés no chão.(...) $\mathrm{O}$ ar será puro, sem o veneno dos canos de descarga, e vai existir apenas a 
contaminação que emana dos medos humanos e das humanas paixões. O povo não será guiado pelos carros, nem programado pelo computador, nem comprado pelo supermercado, nem visto pela TV. A TV vai deixar de ser o mais importante membro da família, para ser tratada como um ferro de passar ou uma máquina de lavar roupas. Vamos trabalhar para viver, em vez de viver para trabalhar. (...)

(Eduardo Galeano. O direito ao delírio)

Segundo CALDART (2007), o debate do trabalho no campo está diretamente relacionado com o da Educação do Campo, por trazer a dimensão da cultura vinculada às relações sociais de produção, ou seja, aos processos produtivos da existência social no campo.

\section{DAS ORIGENS À INSTITUCIONALIZAÇÃO:}

No movimento é sempre difícil precisar quando uma coisa começa; tudo é um processo permanente, e atrás de um fato sempre tem outro... (STEDILE, 1997, Entrevista para a história do MST)

As primeiras iniciativas e atividades na educação escolar daquilo que chamamos de Pedagogia do Movimento Sem Terra ${ }^{\text {ii }}$ de que se têm registro aconteceram no acampamento de Encruzilhada Natalino, no Rio Grande do Sul, na década de 1980, oriundas da ocupação ocorrida em 1979 das Fazendas Macali e Brilhante em Ronda Alta. Naquela época, o MST ainda não estava organizado da maneira como conhecemos atualmente: cada família ainda aprendia pouco a pouco como se organizar em seu Movimento. Ali iniciava-se uma nova fase da luta pela terra no país. Partindo de uma preocupação recorrente do que fazer com tantas crianças - naquele momento, mais de duzentas -, grupos formados por mães passaram a desenvolver atividades que pudessem, de maneira lúdica, integrar as crianças ao acampamento, trazendo suas compreensões sobre aquele momento que estava sendo vivido.

Da Fazenda Anonni, no Rio Grande do Sul, há relatos datados de aproximadamente 1986 que mostram que, a princípio, se organizaram equipes para debater e se debruçar sobre o que fazer com as crianças acampadas e sem escola, num lugar em que não havia perspectivas de estudar. Ali havia 1500 famílias e mais de 1000 crianças: era o maior acampamento já realizado até então. Organizavam-se em Equipes de Trabalho; dentre essas, a Equipe de Educação, na qual pessoas interessadas em trabalhar com as crianças se encontravam e se perguntavam o que fazer com todas aquelas crianças que ainda não conseguiam compreender o que faziam ali e qual o papel daquela luta.

Porém, sabemos não ser suficiente a análise sobre o que é a educação do campo se não nos atentarmos para seu papel para além do espaço escolar. Dessa forma, para compreendermos os contornos dessa história, precisamos olhar para o conjunto do Movimento.

A partir do momento em que percebemos que a escola e a educação residem na construção cotidiana e coletiva dos sujeitos, naturalmente percebemos que, para os Sem Terra, a construção cultural ${ }^{\mathrm{iii}}$ influi diretamente na construção social do indivíduo.

Dessa história nós somos os sujeitos

Lutamos pela vida, pelo que é de direito 
As nossas marcas se espalham pelo chão

A nossa escola, ela vem do coração

(letra da música Educação do Campo)

Em um primeiro momento, foram as famílias sem-terra, compreendendo a necessidade de uma escola que fizesse diferença nas suas vidas, que se mobilizaram para garantir o direito à escola. Naquele momento inicial, mães e professoras tomaram à frente nessa luta, aproximandose depois dirigentes do Movimento e alguns homens, até que as crianças também tomaram à frente dessa luta por sua própria escola, de forma que, enfim, se reconhecessem e transformassem esse espaço de pedra em espelho (IASI, 2008).

Posteriormente, decidiu-se pela produção de uma proposta pedagógica específica para as escolas ocupadas e para a formação desses educadores do $M S T^{i v}$. A criação do Setor de Educação marcou o momento em que essa preocupação transformou-se em tarefa por perceberem que as crianças sem-terra olhavam de uma perspectiva diferente o mundo vivido. Portanto, a relação entre a escola e esses educandos deveria se fazer de maneira também diferenciada, para que enfim, essa educação se tornasse, de fato, "significativa" e "contextualizada".

A luta pela Educação do Campo tomou forma dentro do bojo da luta pela Reforma Agrária, pois foi da ligação com as lutas dos Movimentos Sociais do campo - principalmente o MST - que nasceu a perspectiva de transformação das bases educativas, pela conquista de uma educação que não é a "rural" porque vai para além dos muros da escola e porque é uma luta por um outro campo, o campo dos trabalhadores sem terra que estão em luta, reagindo dentro da lógica excludente no campo brasileiro.

As Licenciaturas em Educação do Campo - A fruta aberta

Grandes coisas simples aprendi contigo, com o teu parentesco com os mitos mais terrestres, com as espigas douradas no vento, com as chuvas de verão e com as linhas da minha mão. Contigo aprendi que o amor reparte mas sobretudo acrescenta, e a cada instante mais aprendo (...) partindo ao meio e unindo os extremos da vida, e mostrando a verdade como uma fruta aberta. (MELLO, 1962)

No ano de 1997, a Universidade Regional do Noroeste do Estado do Rio Grande do Sul/UNIJUI iniciou, através de convênio entre o INCRA/MST/UNIJUI, a primeira turma de formação de professores de assentamentos do MST em nível superior, por meio do Curso de Pedagogia para Formação de Professores do Ensino Fundamental e Coordenadores da Escolarização dos Assentamentos de Reforma Agrária, que logo passou a ser chamado de Pedagogia da Terra. Este primeiro curso de Pedagogia da Terra iniciou-se em 19 de janeiro de 1998, na UNIJUI, com sede na cidade de Ijuí - RS, finalizada em julho de 2001. O termo "Pedagogia da Terra" ganha um sentido próprio, identificando na palavra "terra" o lugar onde os sujeitos do campo constroem suas identidades a partir da produção da sua sobrevivência e de suas lutas. O curso passa a ser denominado assim pelos próprios educandos que criam um jornal com este nome, a fim de enfatizar sua especificidade e origem. 
Mas um nome pode ser apenas um nome; identifica, mas não significa, até que se constroem coletivamente estes significados em um contexto de relações geralmente de contradições e de conflitos. Uma identidade é uma marca de pertencimento a um determinado grupo, que se diferencia de outros ou que se contrapõe a outros grupos, outros traços de cultura, outro jeito de ser. Pode ser, pois, de confirmação ou de resistência ao ambiente social em que se origina. Quando os estudantes do MST passaram a se chamar de "pedagogos" e "pedagogas da terra", estavam demarcando e declarando este pertencimento: antes de universitários somos sem-terras temos a marca da terra e da luta que nos fez chegar até aqui.

(CALDART, 2004, p.25)

A partir de então passam a surgir diversos cursos de graduação em Pedagogia com o protagonismo dessas mulheres e homens da terra, apoiados pelo Programa Nacional de Educação na Reforma Agrária (PRONERA) com a finalidade de "garantir a escolaridade e a formação de educadores (as) para atuar na promoção da educação nas áreas de Reforma Agrária", de acordo com a definição de seu programa, baseado em seu Manual de Operações (BRASIL, 2004).

O objetivo de formação do curso e mote para entrar nessa luta dentro da academia foi garantir a formação de professores para as escolas a serem conquistadas, tomando como referência a LDB 9394/96, em seu artigo 28, que aponta a garantia aos povos do campo de um sistema de ensino adequado à sua diversidade sociocultural, demandando adaptações de organização, metodologias e currículos às peculiaridades da vida rural e interesses dos alunos destas áreas. Para que isso fosse executado, necessário seriam profissionais habilitados para essas questões (perfil/especificidade do educador da escola do campo).

O curso de Licenciatura em Educação do Campo, até então conhecido como Pedagogia da Terra, ganha no dia 21 de novembro de 2005 (data de sua aula inaugural), na Faculdade de Educação da Universidade Federal de Minas Gerais, os contornos da sua primeira turma, nascendo das demandas apresentadas pelo MST. Buscava-se criar uma parceria com o apoio do PRONERA, da UFMG e do INCRA/MG construindo, enfim, um curso de Pedagogia destinado à formação de educadores para o campo, destacando sempre qual a concepção de educação e o projeto de escola do campo, trazendo o Movimento um histórico de já ter - naquele momento dezesseis turmas de Pedagogia da Terra em diferentes Universidades públicas do Brasil.

A "ocupação do latifúndio do saber" teve início nas reuniões ocorridas entre representantes do MST e da UFMG, no ano de 2003. O Projeto Político Pedagógico começa a ser delineado diante de muitos aprendizados a partir das diversas experiências que o curso foi proporcionando, na medida em que foi se estendendo para outros movimentos da Via Campesina.

Devido às especificidades dos educandos, o curso deveria partir - através das concepções fundamentais da Educação do Campo (através da tríade Educação Socialista, Educação Popular e Pedagogia do Movimento) - das situações vivenciadas pelos educandos, organizados a partir da Pedagogia da Alternância. Segundo TEIXEIRA (2008), o surgimento da Pedagogia da Alternância tem suas origens na França, relacionando-se a um movimento datado de 1935, quando um grupo de agricultores franceses insatisfeitos com o sistema educacional por perceberem que a educação a que tinham acesso não atendia às suas demandas organizaram-se com o auxilio de um padre, alternando períodos em que os educandos 
permaneciam na escola com períodos em que retornavam para a propriedade familiar. Portanto, um dos fundamentos básicos dessa organização curricular prevê duas etapas presenciais: o Tempo Escola e o Tempo Comunidade, compreendendo que a educação e a vida cotidiana desses educandos possuem uma articulação indissociável e fundamental para a construção cotidiana da compreensão de mundo e reconhecimento como sujeitos. A Alternância torna possível o diálogo entre diferentes espaços e tempos educativos, cada qual com suas características próprias.

No Brasil, a Alternância teve início no Espírito Santo, com um trabalho de base por volta de 1965/1966, por iniciativa do Padre Humberto Pietrogrande. A década de 60, fortemente marcada pela ditadura militar teve nas lideranças comprometidas o foco da luta para superação do regime autoritário. Naquele momento, inicia- se a estruturação do Movimento de Educação Promocional do Espírito Santo (MEPES), trazendo essa metodologia da Alternância através do desenvolvimento dos Centros Familiares de Formação por Alternância (CEFFAs).

O MEPES acreditava que a participação da comunidade no processo de formação das CEFFAs era fundamental. Dessa forma, das ações comunitárias fundam-se, em 1969, as duas primeiras CEFFAs (que naquele momento ainda eram conhecidas como EFAs - Escolas de Família Agrícola) em Alfredo Chaves e em Olivânia, ambas no Estado do Espírito Santov.

\section{PRONERA - BREVES ABORDAGENS:}

O Programa Nacional de Educação na Reforma Agrária foi criado em 16 de abril de 1998 (SANTOS, 2012), na ocasião, por portaria do Ministério Extraordinário da Política Fundiária (MEPF). O MST, naquele momento histórico, passava por um período importante da luta pela Reforma Agrária, com mobilizações em todo o país, momento em que a sociedade brasileira reconhecia a importância dessas ações devido aos massacres ocorridos em Corumbiara (Rondônia, 1995) e Eldorado dos Carajás (Pará, 1996).

Ficava claro, naquele momento, que o Estado não viabilizava condições básicas para os povos que vivem no campo, e isso se explicitava principalmente nas condições da Educação nas áreas rurais, pela falta de escolas e de educadores, pela inviabilidade de acesso à educação com dignidade, ficando esses indivíduos muitas vezes restritos a frequentarem apenas os anos iniciais, negando-lhes o direito ao acesso a níveis posteriores de escolaridade.

Como o Movimento realiza desde 1990 curso de formação dos educadores, com cursos de nível médio (magistério), e a partir de 1998 também cursos de nível superior (PTerra ${ }^{\mathrm{vi}}$ ) acabou por ter o trabalho da formação de educadores reconhecido em 1995, com o prêmio "Educação e Participação" da Unicef ${ }^{\text {vii }}$. Mobilizados com esse reconhecimento e as lutas que cada vez mais davam frutos, foi realizado, em 1997, o I ENERA ${ }^{\text {viii }}$, graças a uma parceria entre a Unicef, a $\mathrm{UnB}^{\mathrm{ix}}$ e a UNESCO ${ }^{\mathrm{x}}$. O encontro reuniu mais de 700 educadores entre professores de escolas de assentamentos e acampamentos, educadores da alfabetização de jovens e adultos, educadores infantis e todos que trabalhavam junto ao Movimento nos coletivos de Educação, proporcionando trocas de experiências e vivências. Daquele encontro, surgiu a proposta de criação do PRONERA.

Através dos debates, os educadores começaram a notar que a alta taxa de analfabetismo no campo brasileiro era uma constante, o que era preocupante. Ao final do encontro, foi formulado um projeto para erradicação deste analfabetismo nas áreas rurais e, com o objetivo de haver um convênio entre o MST, o INCRA e as Instituições públicas de Ensino Superior, o documento foi apresentado às universidades brasileiras (representadas pelo CRUB), que aprovou o tal projeto. A partir de então, ocorreu a criação do PRONERA, que primeiramente 
tinha por objetivo alfabetizar jovens e adultos nos assentamentos, passando posteriormente a atender outros programas, inclusive de cursos superiores.

A UnB teve muita importância no fortalecimento das bases onde o PRONERA surgiu, pois junto a outras universidades (como UNESP, UFPE, UFPA, UFMG,UFRRJ, UNIJUI, UFS, UFPB, UFSC, UFES, UFV, UFC, UFBA e UFMT), se comprometeu, naquele momento, a desenvolver trabalhos referentes à educação em assentamentos da Reforma Agrária, abrindo espaço para diálogo com o Setor de Educação do Movimento, reafirmando a consolidação do projeto.

E também é através do PRONERA que se viabiliza a construção da Licenciatura em Educação do Campo no Estado do Rio de Janeiro.

\section{TURMA OSEAS CARVALHO - DA SEMENTE PLANTADA NO RIO DE JANEIRO AOS GIRASSÓIS DESSA LUTA}

Artigo III. Fica decretado que, a partir deste instante,

Haverá girassóis em todas as janelas,

Que os girassóis terão direito

A abrir-se dentro da sombra;

E que as janelas devem permanecer, o dia

[inteiro,

Abertas para o verde onde cresce a esperança.

(MELLO, 2009)

\section{CONSTRUINDO PELA LUTA}

A turma pioneira da Licenciatura em Educação do Campo (LEC) no Estado do Rio de Janeiro, que teve início em setembro de 2010, consiste em um curso de graduação para assentados da reforma agrária e povos tradicionais do campo. Foi construído por educadores da Universidade Federal Rural do Rio de Janeiro e os movimentos sociais, povos tradicionais e movimentos sindicais do campo, através de edital do PRONERA em 2009, com duração de 3540 horas em 3 anos - constituídos em 6 Tempos Escola e 6 Tempos Comunidade a partir da Pedagogia da Alternância.

A LEC na Universidade Federal Rural do Rio de Janeiro (UFRRJ) começa a se delinear através das iniciativas e lutas dentro da Academia por parte de alguns docentes (Roberta Lobo, Marília Campos, Lia Teixeira e Ramofly Bicalho) a partir de uma primeira convocação dentro da UFRRJ que ocorreu em 2008, por parte da Reitoria, em função de editais do INCRA que estavam em aberto naquele momento.

Naquele ano de 2008, infelizmente, o projeto não conseguiu se concretizar. Conforme relato da professora Roberta:

(...) Na verdade, a primeira convocação foi em 2008, que a Ana Dantas nos chamou pra juntar em especial com a FETAG e MST, que era uma demanda antiga na demanda nova (...). E ai nos convocam pra pensar o curso. Eu pego essas quatro experiências, estudo, a gente tenta rabiscar uma proposta, mas a gente não se sente seguro pra isso. Primeiro, a FETAG dizendo que tem demanda pra 500, o MST dizendo que tem demanda pra 50. Aquela coisa, e na verdade, a Marilia tava na UFPB, nesse período, participando lá (...). 
E ai não tivemos essas condições, o projeto ficou parado. Quando chega agosto de 2009, o reitor faz uma segunda convocação. Uma convocação onde ele reúne vários setores da Universidade, com o INCRA, com os MS, e a demanda era pro ensino técnico de nível médio, e o curso de LEC. (...) ... o reitor tinha participado de uma reunião logo em 2004 quando o MEC cria a coordenadoria da EdoC.

Então, vários reitores... ele participou, apoiou a idéia, mas imagina, chegou 2009, já tinha muitas experiências, e a Rural com nome de rural, não tinha. Então, ficou muito constrangido numa tal reunião. $\mathrm{E}$ resolveu fazer essa convocação. Bom, da área da educação estava eu, Ramofly, Lia, Marilia. (...)

Dessa forma, em agosto de 2009, a Reitoria faz uma nova convocação reunindo diversos setores da Universidade, apresentando a demanda de diversos editais que abarcavam projetos para o ensino técnico de nível médio, projetos de extensão, bem como projetos de cursos no Ensino Superior.

Depois desse momento, os quatro educadores referenciados pelo depoimento da professora Roberta buscaram fazer reuniões sistemáticas com os Movimentos Sociais, contando com representantes do MST, FETAG (Federação dos Trabalhadores da Agricultura), RECID (Rede de Educação Cidadã), CPT (Comissão Pastoral da Terra), representantes dos Quilombolas e da Secretaria Municipal de Educação de Angra dos Reis representando a Educação Indígena. Naquele momento, foi definido que seriam abertos dois editais: um através do PRONERA para os assentados (60 vagas) e outro para os povos tradicionais (10 vagas) como contrapartida da UFRRJ, na medida em que o Edital do PRONERA era voltado especificamente para assentados de áreas de Reforma Agrária.

A habilitação de Ciências Sociais e Humanidades ganhou o apoio total das Ciências Sociais e, então, acabou por se constituir numa área abarcando a área da História (apoiada pelo Departamento de História do Instituto Multidisciplinar - Nova Iguaçu) e a Sociologia (Departamento de Letras e Ciências - Instituto de Ciências Humanas e Sociais - Seropédica).

$\mathrm{Na}$ construção da outra área de conhecimento (Agroecologia e Segurança Alimentar), o desafio era não se enquadrar dentro do sentido tradicional das Ciências Agrárias referenciado na perspectiva da produção extensiva, da Revolução Verde e do agronegócio. Então, a referência adotada foi aquela construída pelos Movimentos Sociais do Campo: a Agroecologia. É importante mencionar o acúmulo já existente por parte de educadores envolvidos há mais tempo com a questão dentro da UFRRJ, cuja referência dentro do Instituto de Educação (Seropédica) era a professora Lia Teixeira. Dessa forma, a habilitação ganhou destaque a nível nacional pela sua originalidade e necessidade, expressa pelo parecer do PRONERA que aprovou o curso. Outra indicação relevante é o fato desta habilitação da LEC/UFRRJ ter se constituído como o primeiro curso de graduação em Agroecologia dentro da UFRRJ.

A organicidade foi pensada para viabilizar a implementação da Pedagogia da Alternância, visto que o PRONERA não prevê nem o fundamental para esse acompanhamento necessário, os educandos permanecem cerca 45 a 60 dias na Universidade, nos períodos de Tempo Escola, porém a questão dos alojamentos - que é fundamental para a permanência desses educandos na UFRRJ- se torna uma problemática, visto que a residência estudantil é grande mas completamente inchada, devido ao REUNI ${ }^{\mathrm{xi}}$. Portanto, sempre acaba se tornando mais um problema nas mãos da coordenação do curso, ainda que garantida pela reitoria. 
Há ainda a problemática das salas de aula, devido ao inchaço da Universidade. Por isso a LEC conta com a compreensão e o apoio de diversos parceiros também na perspectiva da realização das aulas, como por exemplo a utilização de salas do CAIC (Centro de Apoio Integral a Criança) Paulo Dacorso Filho para viabilizar a ocorrência das aulas do curso.

Quanto ao corpo docente também é preciso destacar as parcerias. Por ter composição multidepartamental, o curso necessita de professores de diferentes áreas, e por ser um curso que se enquadra dentro de um Programa, não tem um quadro de professores fixo. Conta mais uma vez com o envolvimento dos professores, que trabalham como voluntários, portanto a carga horária das disciplinas que lecionam na LEC não conta dentro de seus departamentos (quando são da própria UFRRJ) e quando os professores vêm de outras Universidades chegam até o curso por meio de convites e apenas pela militância e o comprometimento, ou seja, eles não tem liberação alguma para dedicar-se ao curso de Educação do Campo, sendo esse um dos problemas estruturais do curso. Na realidade ou o professor precisa ser muito envolvido com a militância ou são apenas parceiros, voluntários. Essa problemática do professor voluntário acaba refletindo na própria questão da Alternância no curso. Conforme depoimento da professora Marília:

(...)o PRONERA tem limitações muito sérias, é uma conquista dos movimentos sociais, mas é uma política compensatória, é um curso que tem um tempo opressor, não tem um tempo pedagógico que seria o tempo desejável, para os estudantes estarem digerindo, articulando as informações, seria necessário ter um tempo melhor.(...)

O Tempo Comunidade deveria ser acompanhado pelos professores da turma, porém se esse educador já está deixando suas atividades para se dedicar a LEC no Tempo Escola, onde ele ganha apenas mais trabalho (aulas a preparar, trabalhos a corrigir) é inviável pedir que esse professor acompanhe também o Tempo Comunidade, pois nesse momento ele continua suas atividades que ficaram paradas. Então apenas a coordenação permanece tentando se dividir como pode e acompanhando o Tempo Comunidade, cada um em uma regional e obviamente, algumas regionais acabam se adaptando melhor a autogestão que acaba ocorrendo devido às dificuldades da dinâmica da alternância.

A utopia que move tudo isso, e o sonho pra depois dessa turma é conseguir ter um Departamento que a princípio teria como indicativo de nome: Educação do Campo, Movimentos Sociais e Diversidade, podendo abarcar os Assentados, Acampados, Povos Tradicionais, com a graduação e ainda pós-graduação, e uma formação - para além dos muros e burocracias da Academia - continuada, e a participação dos Movimentos Sociais no Departamento, com assento.

O curso tem conclusão prevista para o mês de agosto - quando os educandos apresentarão suas monografias. Dessa forma, é importante dizer que as reflexões aqui apontadas apresentam um dimensão processual, pois dizem respeito ao que foi até o momento, vivenciado.

\section{SEMPRE EM LUTA - OSEAS CARVALHO: PRESENTE, PRESENTE, PRESENTE!}

É preciso não ter medo, é preciso ter a coragem de dizer. (Carlos Mariguella)

A primeira turma de Licenciatura em Educação do Campo do Estado do Rio de Janeiro, no início de seu Tempo Escola 3, começa a perceber a importância da escolha de um nome, que 
pudesse trazer o resgate das memórias e lutas, além de construir a identidade desses educandos, provenientes de tantas realidades diversas, e com tantas histórias de vida. Então, em assembléia foi decidido o nome dado a turma: Oseas Carvalho.

Nesta assembléia o resgate da história de muitas pessoas que sempre seguiram em estado de luta surgiu. Muitos nomes foram lembrados, e a proposta de batismo para a turma era conseguir resgatar essas memórias, dos companheiros tombados na luta para que estes não sejam esquecidos jamais, e que sirvam de referência para permanecer em luta.

O nome foi proposto por companheiros do Quilombo das Guerreiras, devido a proximidade do Oseas também com as lutas da cidade, e principalmente pelo carinho e ligação que sempre teve com essa ocupação urbana, tendo muita proximidade com os companheiros de lá, que hoje estão na LEC.

Oseas, companheiro de luta do Estado do Rio de Janeiro, tinha conhecimento e participação nas lutas do campo e da cidade dentro do Estado. Nascido em Minas Gerais e criado na Baixada Fluminense, em 26 de Julho de 1965, passou parte da juventude no Assentamento Campo Alegre, filho de Dona Geralda e Sr. Adir, teve dentro de casa as primeiras lições e formações de como seguir em luta. Tendo na família referências de peso, a família Carvalho tem mesmo as características dessa árvore, exemplo disso são - além dos pais - as mulheres da família, que são muito guerreiras.

Geralmente o carvalho se transforma em ferramenta para botânicos e geólogos em suas medições dos infortúnios provocados pela natureza no meio ambiente. Ou seja, nesta árvore eles podem encontrar os sinais das tempestades que se abateram sobre a paisagem na qual ela está localizada, pois este espécime é o que mais padece com os efeitos das chuvas fortes.

Por incrível que pareça, quanto mais ele se sujeita às intempéries, mais fortalecido ele sai delas, pois suas raízes se arraigam ao solo a cada tempestade, seu tronco se revigora, e a possibilidade dele ser extraído do solo pelos temporais diminui drasticamente, até se tornar nula. O carvalho se embebe de todas as consequências dos temporais e, assim, adquirem um aspecto desproporcional, exatamente como um ser que tivesse realizado um grande esforço ao longo de sua constituição.(...)

Por esta razão o carvalho é constante fonte de referência para os espiritualistas, pois com seu papel na Natureza acaba se transformando em metáfora de resistência, resignação, submissão diante dos desígnios divinos, uma vez que, a cada assédio das forças naturais ele não se revolta, nem desanima, mas procura triunfar sobre os obstáculos que o perseguem insistentemente. E assim conserva-se sólido e concreto nas florestas e bosques nos quais habita.

SANTANA, Data de publicação: 25/04/2009, http://www.infoescola.com/plantas/carvalho/- consulta em 10-6-12

Oseas, começa a ser tocado pela chama da política, primeiramente dentro da Igreja e logo se filia ao Partido dos Trabalhadores, logo depois disso se envolve cada vez mais na luta dentro do Assentamento onde morava. Mas, não sendo suficiente, vai em frente nas lutas, sempre. Por isso começa a se envolver nas lutas de Campo Belo, ocupação urbana próxima a 
Campo Alegre. Todos dizem que Oseas era um homem "da luta" sobretudo, não fazia parte organicamente de nenhum Movimento Social, colaborava com a mão na massa em movimentos de luta urbana e rural, e recuperava o que todos nós sabemos ser necessário, a união das lutas da classe trabalhadora.

Oseas Carvalho então, passa a morar em Campo Belo, com sua esposa e filha. Porém depois de algumas lutas a família começou a perceber que Oseas se afastava cada vez mais, foi quando ele passa a morar sozinho em Campo Belo. No dia 19 de Março de 2009, Oseas foi assassinado friamente, a tiros, dentro da própria casa, tendo essa sido invadida e saqueada. A família começou então a compreender o porque do afastamento dos últimos tempos, Oseas vinha recebendo constantes ameaças, devido as lutas que vinha encabeçando, nos últimos tempos tinha assumido - também, além da militância que já tinha - a Associação.

E é por conta da luta sem medidas, do conhecimento da importância das lutas do campo e da cidade sabendo das idiossincrasias do Estado do Rio de Janeiro, onde a cidade e o campo, estão se permeando todo o tempo, percebendo o quanto o companheiro Oseas Carvalho lutou a vida inteira para que essas lutas se ligassem no plano da "vida verdadeira", que a turma foi batizada com o nome deste lutador. A fim de que as memórias de companheiros que tombam em luta todos os anos, não se percam é que Oseas vem representar esses Joãos e Marias que dão suas vidas, e que muitas vezes deixam famílias órfãs e os crimes permanecem na impunidade. É deixar essa chama acesa e trazer mais força para todos que estão em luta, através da memória deixada viva de cada luta como a de Oseas que tombou em virtude de sua postura firme e de luta constante, acreditando sempre nos seus ideais e sonhos.

Oseas se foi do plano físico e material, mas deixou muitas sementes plantadas nas lutas de todos cantos do nosso Estado, seja na cidade, seja no campo. Além disso, Oseas deixou seus frutos nessa vida, filhos que se inserem cada vez mais na luta: Jonathan e Suellen Carvalho, aquele que se insere cada vez mais nas lutas junto a juventude na Igreja da comunidade onde mora, e esta militante do MST e educanda e educadora na Turma Oseas Carvalho, que se fortalece cada vez mais diante das histórias de luta da família.

\section{CONCLUINDO SEM FINALIZAR}

Quando o curso de Licenciatura em Educação do Campo chega ao Rio de Janeiro, através da luta dessas educadoras da UFRRJ em conjunto com os Movimentos Sociais, a conjuntura se apresentava completamente desfavorável ao desenvolvimento dessa proposta. A Universidade estava inchada pelos processos do REUNI.

Porém, mesmo diante de tantas dificuldades, executar esse trabalho foi completamente mágico. E não haveria palavras para descrever o que ele significou na minha existência. Realmente me sinto parte desse curso, e dessa luta. Cada um dos educandos se alojou na minha vida e no meu coração.

Compreender os processos de luta e adaptação para a permanência na Universidade foi extremamente fácil, mediante a recepção e o afeto com que fui recebida. Hoje posso dizer que o sentido da luta pela educação do campo, na minha vida foi ressignificado, aprendi muito em cada etapa que acompanhei, em cada dia que passei com a turma, na dinâmica das aulas, onde sempre fui muito bem recebida pelos professores.

Reencontrei o sentido da palavra companheiro, pois todas e todos da turma Oseas Carvalho sempre me trataram como companheira. E eu sempre tentei retribuir da maneira que pude, e espero ainda poder cooperar muito mais nessa construção e nas que virão a partir dessa turma. 
Os trabalhos até de madrugada, as conversas, os conselhos, os amigos e amigas que fiz, sem nunca olhar os Movimentos Sociais, somos sobretudo seres humanos, e esses seres humanos eu amo demais e é com muita emoção que tenho a sensação de que parte da tarefa foi cumprida, hoje eu olho nos olhos dos meus companheiros e me reconheço.

Eu, Lara Douetts, militante, educadora popular, na luta pela construção da educação do campo que necessitamos e que empoderados, fazemos.

i Texto proveniente de trabalho de conclusão de curso apresentado na Primavera de 2012, na Faculdade de Formação de Professores da UERJ.

ii (CALDART,2004)

iii Como se reconhecer como sujeitos dessa história - sim somos Sem Terra!

iv “a expressão educadores do MST (agora já com maior presença masculina), porque ela incluía as professoras, mas não deixava fora esses outros militantes que, não sendo professores da escola, são também trabalhadores e trabalhadoras da educação" (CALDART,2004)

v Segundo ZAMBERLAN (1995), a partir da segunda metade da década de 80 a EFA foi brotando nas mais longínquas e diferentes regiões brasileiras: Alagoas, Amazonas, Rondônia, Amapá, Maranhão, Piauí, Minas Gerais, Paraná, Pernambuco, Ceará e Rio Grande do Norte.

vi Pedagogia da Terra como ficou carinhosamente conhecida entre os educandos/ educadores e militantes

vii Fundo das Nações Unidas para a Infância

viii Encontro Nacional de Educadoras e Educadores da Reforma Agrária

ix Universidade de Brasília

x Organização das Nações Unidas para Educação Ciência e Cultura

xi Programa de Apoio a Planos de Reestruturação e Expansão das Universidades Federais

\section{Referências Bibliográficas}

ALENTEJANO, Paulo. Questão agrária no Brasil do século XXI: uma abordagem a partir da Geografia. 2011.

ANDRADE, Márcia Regina, DI PIERRO, Maria Clara, MOLINA, Mônica Castanha \& JESUS, Sonia Meire. (orgs). Educação na Reforma Agrária em Perspectiva: Uma Avaliação do Programa Nacional de Educação na Reforma Agrária. São Paulo: Ação Educativa, 2004.

O Programa Nacional de Educação na Reforma Agrária em Perspectiva. Dados Básicos para uma Avaliação. Texto de Internet, 2004. 
ARROYO, Miguel, CALDART, Roseli Salete. MOLINA, Mônica Castanha. (orgs). Por uma Educação do Campo. Petrópolis. Rio de Janeiro: Vozes, 2004.

BRASIL, Lei de Diretrizes e Bases, no 9394/96. Brasília, 1996.

Diretrizes Operacionais para a Educação Básica nas Escolas do Campo. Resolução $\mathrm{CNE} / \mathrm{CEB} \mathrm{n}^{\circ} 1,3$ de abril de 2002.

Instituto Nacional de Pesquisa Anísio Teixeira/INEP. Panorama da Educação do Campo. Brasília: Mec, 2007.

. Secretaria de Educação Continuada, Alfabetização e Diversidade/SEDAC. Educação do Campo: Diferenças Mudando Paradigmas. Caderno n². Brasília, Mec, 2007.

Grupo Permanente de Trabalho de Educação do Campo. Referências para uma Política Nacional de Educação do Campo. Cadernos de Subsídios. Brasília, Mec, 2004.

CALDART, R.S; ALENTEJANO, P; PEREIRA, I.B; FRIGOTTO,G (orgs). Dicionário da Educação do Campo. Rio de Janeiro. São Paulo: Expressão Popular, 2012.

CALDART, R. S. Pedagogia do Movimento Sem Terra. $4^{\text {a }}$ ed. São Paulo: Expressão Popular, 2004. 439p.

Campo. 2008, 67p-85p.

Sobre Educação do Campo. In: SANTOS, C. A. (org.) Por uma Educação do Educação do Campo: notas para uma análise de percurso Trab. Educ. Saúde, Rio de Janeiro, v. 7 n. 1, mar/.jun. 2007. p. 35-64.

FREIRE, Paulo. Pedagogia do Oprimido. Rio de Janeiro: Paz e Terra, 1987.

KRÜGER, Marcos Frederico. Melhores poemas Thiago de Mello. São Paulo: Global, 2009.

IASI, Mauro Luis. Ensaios sobre consciência e emancipação. $2^{\circ}$ ed. São Paulo: Expressão Popular, 2011.

,Meta amor fases: coletânea de poemas. $1^{\circ}$ ed. São Paulo: Expressão Popular, 2008.

MELLO, Thiago. Faz escuro mas eu canto. $5^{\circ}$ ed. Rio de Janeiro: Civilização Brasileira, 1978.

MST, Somos sem terra. Caderno do educando. $N^{o}$ 2. $2^{\mathrm{a}}$ ed. São Paulo, 2003. 71p.

MOLINA, Mônica Castanha \& JESUS, Sonia Meire. (orgs). Por Uma Educação do Campo 5. Brasília: Articulação Nacional por uma Educação do Campo, 2004.

MST. Dossiê MST Escola. Documentos e Estudos 1990-2001: Caderno de Educação no 13. Edição Especial. São Paulo: Expressão Popular, 2005.

SETOR DE EDUCAÇÃO DO MST. Dossiê MST Escola. Caderno de educação n ${ }^{\circ} 13.2^{\circ}$ ed. São Paulo: Expressão Popular, 2005. 
TEIXEIRA, Edival Sebastião et al. Estudos sobre Pedagogia da Alternância no Brasil: revisão de literatura e perspectivas para a pesquisa in: Educação e Pesquisa. São Paulo. 2008, mimeo.

ZAMBERLAN, Sérgio. Pedagogia da Alternância: Escola da Família Agrícola. Espírito Santo: MEPES, 1995.

\section{Bibliografia consultada na internet}

http://www.infoescola.com/plantas/carvalho/ - consulta em 10-6-12 